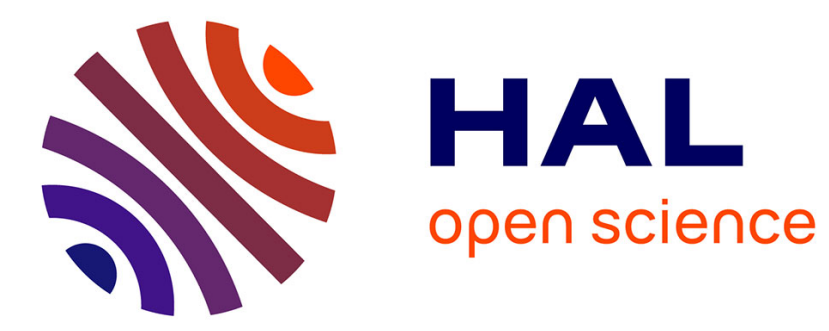

\title{
Impact of water stress on citrus yield
}

García-Tejero, Victor Durán-Zuazo, Arriaga-Sevilla, José Muriel-Fernández

\section{To cite this version:}

García-Tejero, Victor Durán-Zuazo, Arriaga-Sevilla, José Muriel-Fernández. Impact of water stress on citrus yield. Agronomy for Sustainable Development, 2012, 32 (3), pp.651-659. 10.1007/s13593011-0060-y · hal-00930536

\section{HAL Id: hal-00930536 https://hal.science/hal-00930536}

Submitted on 1 Jan 2012

HAL is a multi-disciplinary open access archive for the deposit and dissemination of scientific research documents, whether they are published or not. The documents may come from teaching and research institutions in France or abroad, or from public or private research centers.
L'archive ouverte pluridisciplinaire HAL, est destinée au dépôt et à la diffusion de documents scientifiques de niveau recherche, publiés ou non, émanant des établissements d'enseignement et de recherche français ou étrangers, des laboratoires publics ou privés. 


\title{
Impact of water stress on citrus yield
}

\author{
Iván García-Tejero • Victor Hugo Durán-Zuazo • \\ Javier Arriaga-Sevilla • José Luis Muriel-Fernández
}

Accepted: 22 September 2011 /Published online: 25 October 2011

(C) INRA and Springer-Verlag, France 2011

\begin{abstract}
Water shortage is becoming a severe problem in arid and semi-arid regions worldwide, reducing the availability of agricultural land and water resources. Deficit irrigation strategies can improve water-use efficiency and the sustainability of agro-ecosystems, although it is important to model the effects on yield loss due to irrigation water restrictions. This work estimates the water production function in citrus trees, determining the relationship between plant water stress and yield depression, as well as establishing a mathematical model for each phenological stage considered (flowering, fruit growth and ripening), and for the entire productive process. For three consecutive years (2006-2008), four regulated deficit irrigation treatments plus a control (100\% crop water evapotranspiration $\left(\mathrm{ET}_{\mathrm{C}}\right)$ ) were implemented in 13-year-old citrus trees (Citrus sinensis L. Osb. cv. Navelina). Different water production functions were determined for each phenological stage, establishing the relationship between the irrigation water stress and crop yield. Our results show that the fruit growth and flowering stages were the most sensitive periods in relation to irrigation water deficit and yield loss. Water stress close to $50 \%$ of $\mathrm{ET}_{\mathrm{C}}$ during the flowering stage would impose a yield loss of up to $20 \%$, whereas this same water stress level during the fruit growth or ripening stages would result in yield losses of nearly $10 \%$ and $6 \%$, respectively. The adjustment with cross terms $\left(r^{2}=0.87\right)$ estimated the yield loss with good accuracy, being very similar to data measured in each study season. Consequently, the combined effect of deficit irrigation in different
\end{abstract}

I. García-Tejero • V. H. Durán-Zuazo $(\bowtie) \cdot J$. Arriaga-Sevilla •

J. L. Muriel-Fernández

IFAPA Centro "Las Torres-Tomejil",

Ctra. Sevilla-Cazalla, Km. 12,2. 41200 Alcalá del Río,

Sevilla, Spain

e-mail: victorh.duran@juntadeandalucia.es stages would be an additive-multiplicative model, considering that the effect of water stress in previous periods determined the crop yield response. Our model indicated that the crop water production function under deficit irrigation programmes would have a quasi-linear relation for water deficits below to $40 \% \mathrm{ET}_{\mathrm{C}}$. The previous model functions did not enable us to establish an accurate relationship when the water stress was applied in different phenological stages. Thus, this new interpretation is valuable to improve our knowledge and predict the impact of regulated deficit irrigation and have potential application in precision water stress and sustainable irrigation scheduling for citrus.

Keywords Citrus · Seasonal yield response factors · Water production functions $\cdot$ Deficit irrigation $\cdot$ Water-use efficiency

\section{Introduction}

Under Mediterranean conditions, crop growth is not limited by light, while water availability constitutes the most limiting factor for plant development. In this sense, it is necessary to apply different strategies for reducing water consumption and maximizing the water-use efficiency by encouraging sustainable practices (García-Tejero et al. 2011a). Deficit irrigation (DI) has been widely demonstrated to be effective and sustainable under limiting water conditions by maximizing water productivity while stabilizing yield (García-Tejero et al. 2011b). Many authors have reported that the response of citrus to DI depends mainly on the degree of water stress endured by the crop at different phenological stages (Goldhamer and Salinas 2000). Among DI strategies, regulated deficit irrigation (RDI) is the most common practice used for saving water in many tree crops. Under 
these strategies, the water stress applied depends mainly on the crop phenology, and the different effects caused by this strategy are closely related to timing, duration and crop physiological status, taking into account the maximum evapotranspirative periods and the most critical growth stages, in which water should not be withheld (Chalmers et al. 1986). Although the effects of these practices have been widely studied in several crops, its agricultural application is still in the early stage, as certain issues remain to be clarified. One concerns the possibility of predicting crop yield after water stress during different phenological periods. Doorenbos and Kassam (1979) established an equation to predict the crop productivity as a response to water use, based on the equation proposed by Stewart et al. (1977), which defined the proportionality factor between the yield loss and the related evapotranspiration reduction $\left(K_{Y}\right)$.

Doorenbos and Kassam (1979) reported $K_{Y}$ values for several crops, for individual growth stages, as well as for the total growing season. Therefore, with these observations taken into account, different modelling equations can be established for predicting the effects of water deficit when applied at different phenological stages. These models would predict the yield loss $\left(Y_{i}\right)$ when the available water supply is not sufficient to cover the total crop water demand. In this sense, it would be necessary to consider the timing to apply the water deficit during a specific growth stage, as the yield response depends on crop sensitivity during certain periods. Jensen (1968) proposed an additive model based on crop transpiration for evaluating the effects of irrigation at different stages. This method evaluated crop transpiration at different stages in relation to yield reduction. This model showed different linear relationships, in which the slope value was proportional to the DI effects on crop yield, allowing comparisons of similar deficit transpiration levels for different crops.

In the present work, we seek to model water stress and yield reduction, taking into account the results found in different RDI treatments over three consecutive years. Thus, the objectives of this study are to establish the crop water production functions, placing special emphasis on interactions of water stress at different phenological stages. Also, the loading of each growth stage (flowering, fruit growth and ripening) is quantified when water stress is applied to the crop, offering a new approach for examining the impact of water stress on the corresponding phenological stage.

\section{Material and methods}

\subsection{Experimental site}

The trial was conducted for three consecutive years, in a commercial orchard of mature orange trees (Citrus sinensis L. Osb. cv. Navelina) grafted onto Carrizo citrange ( $C$. sinensis L. Osb. $\times$ Poncirus trifoliata Raf.), located in the Guadalquivir river basin, SW Spain $\left(37^{\circ} 44^{\prime} 4.59^{\prime \prime} \mathrm{N} ; 5^{\circ} 12^{\prime}\right.$ $\left.35.24^{\prime \prime} \mathrm{W}\right)$. The trees were planted 10 years prior to the study, spaced at $6 \times 5 \mathrm{~m}$ and drip-irrigated by two pipe lines with pressure-compensating emitters. The average tree height was $3 \mathrm{~m}$, with a canopy diameter of $4 \mathrm{~m}$. The orchard was planted on ridges of $0.3 \mathrm{~m}$ high, with a NW-SE spatial orientation. The shaded soil surface area and wet drip zone were $30 \%$ and $17 \%$, respectively, of the total. The soil at the experimental site is a typical Fluvisol (FAO 1998), with sandy clay loam texture (350 $\mathrm{g} \mathrm{kg}^{-1}$ sand; $400 \mathrm{~g} \mathrm{~kg}^{-1}$ silt; $250 \mathrm{gkg}^{-1}$ clay) and organic matter content below to $15 \mathrm{~g} \mathrm{~kg}^{-1}$. It is $1.5 \mathrm{~m}$ deep, with a field capacity and wilting point of 235 and $100 \mathrm{~mm} \mathrm{~m}^{-1}$ and with plant roots growing predominantly within $0.6 \mathrm{~m}$ from the surface.

The local climate is Mediterranean dry, with an average potential evapotranspiration $\left(\mathrm{ET}_{\mathrm{o}}\right)$ of $1,500 \mathrm{~mm} \mathrm{year}^{-1}$ and annual rainfall of $475 \mathrm{~mm}$, distributed mainly from late autumn to early spring, with a high inter-annual variability. The thermal range was broad, with average temperatures being $10^{\circ} \mathrm{C}$ in winter and $35^{\circ} \mathrm{C}$ in summer, often exceeding $40^{\circ} \mathrm{C}$ during the hours of maximum solar radiation.

\subsection{Experimental design and RDI treatments}

The experimental design was a randomized complete block, with five replicates per treatment. The experimental unit had three rows, with five trees per row, and the three central trees (central row) were established for measuring fruit yield.

Four RDI treatments were applied from April to harvest (mid-December), irrigated according to different water stress levels (WSL) at different phenological stages (flowering, fruit growth and ripening), which were defined as the ratio of water supplied at each phenological stage referring to crop water evapotranspiration $\left(\mathrm{ET}_{\mathrm{C}}\right)$ :

(a) RDI-1, which received a WSL of 0.45 during flowering and ripening periods and 0.30 during the fruit growth stage

(b) RDI-2, which received a WSL of 0.45 during flowering period and 0.30 during the fruit growth and ripening stages

(c) RDI-3, which received a WSL of 0.45 during flowering and fruit growth stage and 0.30 during the ripening period

(d) RDI-4, which received a WSL of 0.30 during flowering and fruit growth stage and 0.45 during the ripening period

Additionally, a fully irrigated treatment (control) was established, this being irrigated at $100 \%$ of $\mathrm{ET}_{\mathrm{C}}$.

The different stages considered correspond to the main phenological periods in citrus crop. The first stage covers the flowering and fruit setting period. The fruit growth stage spans the months of July and August, in which the fruit set reach maximum size. Finally, during the ripening period, 
several chemical changes occur in the fruit, which promote a colour change and an increase in total soluble solids.

The seasonal values of $\mathrm{ET}_{\mathrm{C}}$ were determined using the Doorenbos and Pruitt (1977) equation, recording weather data at an automated station near the orchard. Crop coefficients ranged between 0.50 from March to May, 0.55 from June to October and 0.50 in November and December. Also, a reduction coefficient of 0.60 was calculated as twice the ratio of the shaded surface area at noon (Castel 1991).

\subsection{Statistical analysis}

At the end of each season, fruit yield, water productivity and irrigation water productivity were determined. An exploratory and descriptive analysis was made of yield followed by an ANOVA with a mean separation analysis using Tukey's honestly significant difference (HSD) test.

The main goal was to determine a yield function of the water stress level applied. The optimal function was determined through the minimization of the root mean squared (RMS) error:

$f(x)=\widehat{f}(x)$ when $E_{\mathrm{RMS}}=\sum_{i} y_{i}-\widehat{f}\left(x_{i}\right)$ is a minimum.

where $\widehat{f}(x)$ is each possible yield function, $x=x(t)$ is the water stress level (that may depend on time) and $y_{i}$ is the known yield loss due to the application of $x_{i}$ stress level.

\subsection{Modelling the crop production function}

Different relationships between the water stress applied and crop loss were determined, taking into account that different water stress levels were defined at different stages: flowering, fruit growth and ripening, isolating the effects of water stress in each stage:

$P=f(\vec{x})=f\left(x_{\mathrm{f}}, x_{\mathrm{g}}, x_{\mathrm{r}}\right)$

where $P$ is the yield loss and $x_{i}$ is the water stress level at the $i$ stage and $\mathrm{f}, \mathrm{g}$ and $\mathrm{r}$ signify flowering, fruit growth and ripening stages, respectively.

We established quasi-linear, quadratic and cubic functions, attaining the best accuracy with the latter. MATLAB ${ }^{\circledR}$ software minimization functions and Sequential Quadratic Programming algorithm (Fletcher and Powell 1963; Gill et al. 1981) were used to estimate most suitable functions.

The general equation for each stage was defined as follows:

$f_{k}\left(x_{k}\right)=a_{k} x_{k}^{3}+b_{k} x_{k}^{2}+c_{k} x_{k}$

where $a_{k}, b_{k}$ and $c_{k}$ are the yield factors defined for a cubic relationship in a single stage. Taking into account that when there is no water stress, there is not yield loss, and therefore, there is no ordinate at the origin.

\subsection{Model by adjustment without cross terms}

The general equation that includes the three stages is the addition of the previous equation by:

$f(\vec{x})=f\left(x_{\mathrm{f}}, x_{\mathrm{g}}, x_{\mathrm{r}}\right)=f_{\mathrm{f}}\left(x_{\mathrm{f}}\right)+f_{\mathrm{g}}\left(x_{\mathrm{g}}\right)+f_{\mathrm{r}}\left(x_{\mathrm{r}}\right)$

Four constraints for the $f_{k}\left(x_{k}\right)$ were considered:

1. In the range of interest $([0,1])$, the functions must monotonically increase as follows:

$f_{k}^{\prime}\left(x_{k}\right) \geq 0, \forall x_{k} \in[0,1] \rightarrow 3 a_{k} x_{k}^{2}+2 b_{k} x_{k}+c_{k} \geq 0, \forall x_{k} \in[0,1]$.

2. Productivity cannot be reduced by a factor greater than 1 :

$$
f_{k}\left(x_{k}\right) \leq 1, \forall x_{k} \in[0,1] .
$$

3. As defined, the function equals 0 in $x=0$ (Co. 3)

4. The addition of the three functions must be less than 1 , and the function monotonically increases by:

$$
\begin{array}{r}
f_{\mathrm{f}}\left(x_{\mathrm{f}}=1\right)+f_{\mathrm{g}}\left(x_{\mathrm{g}}=1\right)+f_{\mathrm{r}}\left(x_{\mathrm{r}}=1\right) \leq 1 \\
\rightarrow f(1,1,1)=\sum_{k=\mathrm{f}, \mathrm{g}, \mathrm{r}} a_{k}+b_{k}+c_{k} \leq 1
\end{array}
$$

Given these four constraints, the function to minimize is:

Min : $E_{\mathrm{RMS}}=E_{\mathrm{r}} \cdot E_{\mathrm{r}}^{T}$

$E_{\mathrm{r}}=(A X-B) \varnothing B$

where:

$$
\begin{aligned}
A & =\left[k_{i j}^{n}\right], B=\left[y_{i}\right]^{T} ; \quad i=1 \ldots 4 ; j=\mathrm{f}, \mathrm{g}, \mathrm{r} ; n=1 \ldots 3 \\
X & =\left[\begin{array}{lllllllll}
a_{\mathrm{f}} & a_{\mathrm{g}} & a_{\mathrm{r}} & b_{\mathrm{f}} & b_{\mathrm{g}} & b_{\mathrm{r}} & c_{\mathrm{f}} & c_{\mathrm{g}} & c_{\mathrm{r}}
\end{array}\right]^{T}
\end{aligned}
$$

$k_{i j}$ are the stress levels applied in stage $j$ from experiment $i$ and $M \varnothing N$ implies a Hadamard (element-wise) division of two vectors $M$ and $N$ (Byung-Gook and Yunbeom 1998). Finally, in accordance with Moriasi et al. (2007), the NashSutcliffe efficiency index $\left(R^{2}\right)$ was used to quantify the efficiency of the resulting model (Nash and Sutcliffe 1970).

\subsection{Model by adjustment adding cross terms}

The main assumption is that water stress induced at two different phenological stages should have a stronger effect on yield loss than when this water stress is applied at only one stage, but it could have a weaker effect than the simple addition of the two separate components. Given that $f$ is a yield loss and if stress is induced in the first stage, 
production will be reduced. Consequently, water stress induced in following periods would not affect the part of the yield that has already been lost.

$$
\begin{aligned}
& f\left(x_{\mathrm{f}}, 0,0\right)=f_{\mathrm{f}}\left(x_{\mathrm{f}}\right) \rightarrow P\left(t_{1}\right)=1-f\left(x_{\mathrm{f}}, 0,0\right)=1-f_{\mathrm{f}}\left(x_{\mathrm{f}}\right) \\
& f\left(x_{\mathrm{f}}, x_{\mathrm{g}}, 0\right)=f_{\mathrm{f}}\left(x_{\mathrm{f}}\right)+f_{\mathrm{g}}\left(x_{\mathrm{g}}\right) P\left(t_{1}\right) \rightarrow P\left(t_{2}\right)=1-f\left(x_{\mathrm{f}}, x_{\mathrm{g}}, 0\right) \\
& f\left(x_{\mathrm{f}}, x_{\mathrm{g}}, x_{\mathrm{r}}\right)=f_{\mathrm{f}}\left(x_{\mathrm{f}}\right)+f_{\mathrm{g}}\left(x_{\mathrm{g}}\right) P\left(t_{1}\right)+f_{\mathrm{r}}\left(x_{\mathrm{r}}\right) P\left(t_{2}\right)
\end{aligned}
$$

where $P(t)$ is a function describing the effect of the water stress on yield (not the yield loss); $t_{1}$ and $t_{2}$ is the end of flowering and fruit growth stage, respectively, and $P\left(t_{1}\right), P$ $\left(t_{2}\right)$ is the resulting yield when water stress is applied in the first two stages. Clearly, as $t_{0}$ is the moment before applying any water stress, then $P\left(t_{0}\right)=1$. Equation 5 is then represented by:

$$
\begin{aligned}
& f\left(x_{\mathrm{f}}, x_{\mathrm{g}}, 0\right)=f_{\mathrm{f}}\left(x_{\mathrm{f}}\right)+f_{\mathrm{g}}\left(x_{\mathrm{g}}\right) \mathrm{P}\left(\mathrm{t}_{1}\right)=f_{\mathrm{f}}\left(x_{\mathrm{f}}\right)+f_{\mathrm{g}}\left(x_{\mathrm{g}}\right)-f_{\mathrm{f}}\left(x_{\mathrm{f}}\right) f_{\mathrm{g}}\left(x_{\mathrm{g}}\right) \\
& f(\vec{x})=f\left(x_{\mathrm{f}}, x_{\mathrm{g}}, x_{\mathrm{m}}\right)=f_{\mathrm{f}}\left(x_{\mathrm{f}}\right)+f_{\mathrm{g}}\left(x_{\mathrm{g}}\right) P\left(t_{1}\right)+f_{\mathrm{m}}\left(x_{\mathrm{m}}\right) P\left(t_{2}\right) \rightarrow \\
& f(\vec{x})=f_{\mathrm{f}}\left(x_{\mathrm{f}}\right)+f_{\mathrm{g}}\left(x_{\mathrm{g}}\right)+f_{\mathrm{r}}\left(x_{\mathrm{r}}\right)-f_{\mathrm{f}}\left(x_{\mathrm{f}}\right) f_{\mathrm{g}}\left(x_{\mathrm{g}}\right)-f_{\mathrm{f}}\left(x_{\mathrm{f}}\right) f_{\mathrm{r}}\left(x_{\mathrm{r}}\right) \\
& -f_{\mathrm{g}}\left(x_{\mathrm{g}}\right) f_{\mathrm{r}}\left(x_{\mathrm{r}}\right)++f_{\mathrm{f}}\left(x_{\mathrm{f}}\right) f_{\mathrm{g}}\left(x_{\mathrm{g}}\right) f_{\mathrm{r}}\left(x_{\mathrm{r}}\right)
\end{aligned}
$$

The complete equation of the yield loss is represented by:

$$
f\left(x_{\mathrm{f}}, x_{\mathrm{g}}, x_{\mathrm{r}}\right)=\sum_{i=\mathrm{f}, \mathrm{g}, \mathrm{r}} f_{i}\left(x_{i}\right)+\sum_{\substack{i=\mathrm{f}, \mathrm{g}, \mathrm{r} \\ i \neq j}} f_{i j}\left(x_{i}, x_{j}\right)+f_{\mathrm{fgr}}\left(x_{\mathrm{f}}, x_{\mathrm{g}}, x_{\mathrm{r}}\right)
$$

and $f_{i}\left(x_{i}\right)$ can be determined with constraints previously defined.

If those constraints are guaranteed, then the effect of water stress in two stages has to be greater than the effect of water stress at either of the stages, which is already ensured by constraint $2,0 \leq f_{i}\left(x_{i}\right) \leq 1, \forall x_{i} \in[0,1]$. Also, the superposition of two effects has to be monotonically increasing, which is insured by constraints 1 and 2 , $\left\{\begin{array}{l}0 \leq \frac{\mathrm{d} f_{i}\left(x_{i}\right)}{\mathrm{d} x_{i}} \leq 1 \\ 0 \leq f_{j}\left(x_{j}\right) \leq 1\end{array}\right\}, \forall\left(x_{i}, x_{j}\right) \in[0,1]^{2}$

Partial derivatives ensure that the constant stress in one stage and the stress in the other stage induce a monotonic increase in the yield loss function. Also, it should be verified that the yield loss is not higher than 1 , which is ensured by constraint 2 .

$$
\begin{aligned}
& f_{i j}+f_{j}+f_{i}=f_{i}+f_{j}-f_{i} f_{j} \leq 1, \forall\left(x_{i}, x_{j}\right) \in[0,1]^{2} \rightarrow f_{j}\left(1-f_{i}\right) \leq 1-f_{i} \\
& 1-f_{i} \geq 0, \forall x_{i} \in[0,1] \rightarrow f_{j}\left(x_{j}\right) \leq 1, \forall x_{j} \in[0,1]
\end{aligned}
$$

Adding the cross terms for three stages (flowering, fruit growth and ripening), the effect of water stress has to be greater than the effect on any two stages alone, which leads to Eq. 7, ensured by constraint 2 .

$f_{i}+f_{j}+f_{k}-f_{i} f_{j}-f_{i} f_{k}-f_{j} f_{k}+f_{i} f_{j} f_{k} \geq f_{i}+f_{j}+f_{i} f_{j} \rightarrow f_{k}-f_{i} f_{k}-f_{j} f_{k}+f_{i} f_{j} f_{k} \geq 0$

$f_{k}\left(x_{k}\right) \geq 0, \forall x_{k} \in[0,1] \rightarrow 1-f_{i}-f_{j}+f_{i} f_{j} \geq 0 \rightarrow f_{i}+f_{j}-f_{i} f_{j} \leq 1, \forall\left(x_{i}, x_{j}\right) \in[0,1]^{2}$

The yield loss has 1 as the maximum, which leads to Eq. 6, ensured by constraint 2 .

$$
\begin{aligned}
& f(\vec{x})=f_{\mathrm{f}}+f_{\mathrm{g}}+f_{\mathrm{r}}-f_{\mathrm{f}} f_{\mathrm{g}}-f_{\mathrm{f}} f_{\mathrm{r}}-f_{\mathrm{g}} f_{\mathrm{r}}+f_{\mathrm{f}} f_{\mathrm{g}} f_{\mathrm{r}} \leq 1, \forall\left(x_{\mathrm{f}}, x_{\mathrm{g}}, x_{\mathrm{r}}\right) \in[0,1]^{3} \\
& 1-f_{\mathrm{g}}\left(x_{\mathrm{g}}\right) \geq 0, \forall x_{\mathrm{g}} \in[0,1] \rightarrow f_{\mathrm{f}}\left(1-f_{\mathrm{g}}\right)+f_{\mathrm{r}}\left(1-f_{\mathrm{g}}\right)+f_{\mathrm{r}} f_{\mathrm{f}}\left(1-f_{\mathrm{g}}\right) \\
& \leq 1-f_{\mathrm{g}} \rightarrow f_{\mathrm{f}}+f_{\mathrm{r}}+f_{\mathrm{f}} f_{\mathrm{r}} \leq 1, \forall x_{\mathrm{f}}, x_{\mathrm{r}} \in[0,1]^{2}
\end{aligned}
$$

Unfortunately, it is not feasible to translate some of these constraints into linear conditions. The condition 1 $\left(\frac{\mathrm{d} f_{k}\left(x_{k}\right)}{\mathrm{d} x_{k}} \geq 0, \forall x \in[0,1]\right)$ has to be satisfied at each point of the interval $[0,1]$, resulting in infinite linear constraints. For this drawback to be avoided, a sufficient number of points should be chosen (i.e., $0,0.5,1$ ) to evaluate the constraints at those points. The constraints were stored in a Matlab script file (.m file), resulting in 20 constraints for the nine variables.
The second minimization problem proposed remains defined by Eq. 4, but the matrices changed so much that the function should be redefined:

Min : $\quad E_{\mathrm{RMS}}=E_{\mathrm{r}} \cdot E_{\mathrm{r}}^{T}$

$E_{\mathrm{r}}=\widehat{F} \varnothing B$

where:

$B=\left[\begin{array}{llll}y_{1} & y_{2} & y_{3} & y_{4}\end{array}\right]^{T} F_{i}=\left[a_{i} k_{j i}^{3}+b_{i} k_{j i}^{2}+c_{i} k_{j i}\right], \quad i=\mathrm{f}, \mathrm{g}, \mathrm{r} ; j=1 \ldots 4$

$P_{1}=\left[\begin{array}{llll}1 & 1 & 1 & 1\end{array}\right]^{T}-F_{f}, \quad P_{2}=\left[\begin{array}{llll}1 & 1 & 1 & 1\end{array}\right]^{T}-\left(F_{\mathrm{f}}+F_{\mathrm{g}} \odot P_{1}\right)$

$\widehat{F}=F_{\mathrm{f}}+F_{\mathrm{g}} \odot P_{1}+F_{\mathrm{r}} \odot P_{2}$

where $M \odot N$ is the Hadamard (element-wise) product of two vectors $M$ and $N$ (Byung-Gook and Yunbeom 1998).

Finally, we evaluate the Nash-Sutcliffe ' $R{ }^{2}$; also another efficiency index was redefined for separable models (Nash and Sutcliffe 1970), ' $r^{2}$, , which is a 
quantitative description of the improvement induced by the cross terms to our model.

\section{Results and discussion}

\subsection{Yield and regulated deficit irrigation treatments}

The effect of water deficit on fruit yield and water productivity was evident with significant differences between the RDI treatments (Table 1). Some treatments with similar irrigation water applied promoted different yields, this being related to the irrigation strategy followed in each treatment. García-Tejero et al. (2008) demonstrated the importance of the time course of the water stress endured by the crop. The best results corresponded to RDI-4, in which severe water stress was applied during the ripening period, the crop receiving around $55 \% \mathrm{ET}_{\mathrm{C}}$, while the water restrictions during previous stages were below $70 \% \mathrm{ET}_{\mathrm{C}}$. Other RDIs with similar irrigation water applied showed no productive response as positive as RDI-4. In this sense, RDI-2, which was irrigated covering $55 \% \mathrm{ET}_{\mathrm{C}}$ during the flowering period, and water savings closely to $30 \% \mathrm{ET}_{\mathrm{C}}$ during fruit growth and ripening period received, on average, similar irrigation water as applied to RDI-4 but registered more restrictive yield values (reductions closely to $18 \%$ on average). This emphasises the importance of the physiological stage in which water stress is applied. The
RDI-3 treatment provided a water savings of nearly $130 \mathrm{~mm}$ and a yield reduction approaching $22 \%$, whereas RDI-1, averaging $117 \mathrm{~mm}$ of water saving, reached yield reduction values similar to those of RDI-2. However, this treatment had an irrigation water consumption of $13 \mathrm{~mm}$ higher than in RDI-1. These treatments had the same irrigation restrictions during the flowering and fruit growth periods, respectively, with a partial recovery of irrigation during the ripening stage in RDI-2. However, this fact did not substantially boost yield over that of RDI-1. Therefore, the irrigation load during the ripening period would not be especially significant in comparison with the other stages considered. Finally, RDI-4 showed yield reductions of $8.0 \%$ on average, with irrigation water savings of close to $101 \mathrm{~mm}$. It bears remarking that the most severe restrictions in this treatment were applied during the ripening period, underlining the great importance of flowering and fruit growth stages for fruit yield, rather than the ripening period.

The overall effects of water stress on yield were closely related to the phenological stages at which the stress was applied according to the results shown by GonzálezAltozano and Castel (2000). On the other hand, GonzálezAltozano and Castel (2003), studying 'Clementina de Nules' citrus trees, argued that the main effects of DI during the ripening period were reflected mainly in fruit size, with yield reductions of close to $25 \%$ when trees were irrigated to cover $25 \% \mathrm{ET}_{\mathrm{C}}$, whereas fruit yield substan-
Table 1 Deficit irrigation effects on yield and water productivity during the 3-year monitoring period
Within each column, different letters indicate significant differences at $p \leq 0.05$ by Tukey's (HSD) test

$R D I$ regulated deficit irrigation, $W P$ water productivity, IWP irrigation water productivity

\begin{tabular}{lcccccc}
\hline Treatments & $\begin{array}{l}\text { Irrigation } \\
(\mathrm{mm})\end{array}$ & $\begin{array}{l}\text { Irrigation+rain } \\
(\mathrm{mm})\end{array}$ & $\begin{array}{l}\text { Yield } \\
\left(\mathrm{kg} \mathrm{tree}^{-1}\right)\end{array}$ & $\begin{array}{l}\text { Yield reduction } \\
(\%)\end{array}$ & WP $\left(\mathrm{g} \mathrm{L}^{-1}\right)$ & ${\text { IWP }\left(\mathrm{g} \mathrm{L}^{-1}\right)}$ \\
\hline 2006 & & & & & & \\
RDI-1 & 180 & 513 & $125.2 \mathrm{bc}$ & 18.7 & $8.1 \mathrm{c}$ & $23.2 \mathrm{~b}$ \\
RDI-2 & 209 & 542 & $130.9 \mathrm{~b}$ & 14.9 & $9.7 \mathrm{a}$ & $25.1 \mathrm{a}$ \\
RDI-3 & 174 & 507 & $121.9 \mathrm{c}$ & 20.8 & $8.0 \mathrm{c}$ & $23.3 \mathrm{~b}$ \\
RDI-4 & 215 & 548 & $142.2 \mathrm{a}$ & 7.6 & $8.6 \mathrm{~b}$ & $22.0 \mathrm{~b}$ \\
C-100 & 311 & 644 & $153.9 \mathrm{a}$ & - & $8.0 \mathrm{c}$ & $16.5 \mathrm{c}$ \\
2007 & & & & & & \\
RDI-1 & 207 & 470 & $154.5 \mathrm{~b}$ & 15.3 & $10.9 \mathrm{~b}$ & $24.9 \mathrm{~b}$ \\
RDI-2 & 212 & 475 & $153.2 \mathrm{~b}$ & 16.0 & $10.8 \mathrm{~b}$ & $24.1 \mathrm{~b}$ \\
RDI-3 & 183 & 446 & $147.7 \mathrm{c}$ & 19.0 & $11.0 \mathrm{~b}$ & $26.9 \mathrm{a}$ \\
RDI-4 & 215 & 478 & $169.6 \mathrm{ab}$ & 7.0 & $11.8 \mathrm{a}$ & $26.3 \mathrm{a}$ \\
C-100 & 318 & 581 & $182.4 \mathrm{a}$ & & $10.4 \mathrm{c}$ & $19.1 \mathrm{c}$ \\
2008 & & & & & & \\
RDI-1 & 214 & 539 & $129.8 \mathrm{~b}$ & 17.8 & $8.0 \mathrm{~b}$ & $20.2 \mathrm{~b}$ \\
RDI-2 & 219 & 544 & $121.4 \mathrm{~b}$ & 23.1 & $7.2 \mathrm{c}$ & $18.4 \mathrm{c}$ \\
RDI-3 & 185 & 510 & $117.2 \mathrm{c}$ & 25.8 & $7.7 \mathrm{c}$ & $21.1 \mathrm{a}$ \\
RDI-4 & 219 & 544 & $141.3 \mathrm{a}$ & 10.5 & $8.6 \mathrm{a}$ & $21.5 \mathrm{a}$ \\
C-100 & 322 & 647 & $157.9 \mathrm{a}$ & & $8.1 \mathrm{~b}$ & $16.3 \mathrm{~d}$ \\
\hline & & & & & & \\
\hline
\end{tabular}


tially diminished when water stress was applied during the flowering and fruit growth period.

Regarding water productivity, in terms of irrigation and total water applied (irrigation and rainfall), was especially marked by RDI (Table 1). However, the most appreciable differences were detected in irrigation water productivity, demonstrating the great importance of irrigation water distribution during the different phenological periods. On average, DI promoted significant increases in irrigation water productivity. Treatments RDI-3 and RDI-4 were the irrigation strategies that registered the best results compared with the control treatment. This was due mainly to the significant irrigation water savings in RDI-3 and fruit yield values in RDI-4, respectively.

\subsection{Adjustment without cross terms}

Having established the importance of water stress distribution in the different phenological periods, different functions were defined for estimating the water stress load on each of them. Moreover, these functions enable the estimation of the yield loss depending on the water restriction level applied at each stage. Figure 1 shows the results in terms of relative error vector minimization estimated with cubic polynomial functions:

$$
\begin{aligned}
& f_{\mathrm{f}}\left(x_{\mathrm{f}}\right)=-0.5139 x_{\mathrm{f}}^{3}+1.0372 x_{\mathrm{f}}^{2} \\
& f_{\mathrm{g}}\left(x_{\mathrm{g}}\right)=0.02029 x_{\mathrm{g}}^{3}-0.1577 x_{\mathrm{g}}^{2} \\
& f_{\mathrm{r}}\left(x_{\mathrm{r}}\right)=0.3744 x_{\mathrm{r}}^{3}-0.3931 x_{\mathrm{r}}^{2}+0.1348 x_{\mathrm{r}}
\end{aligned}
$$

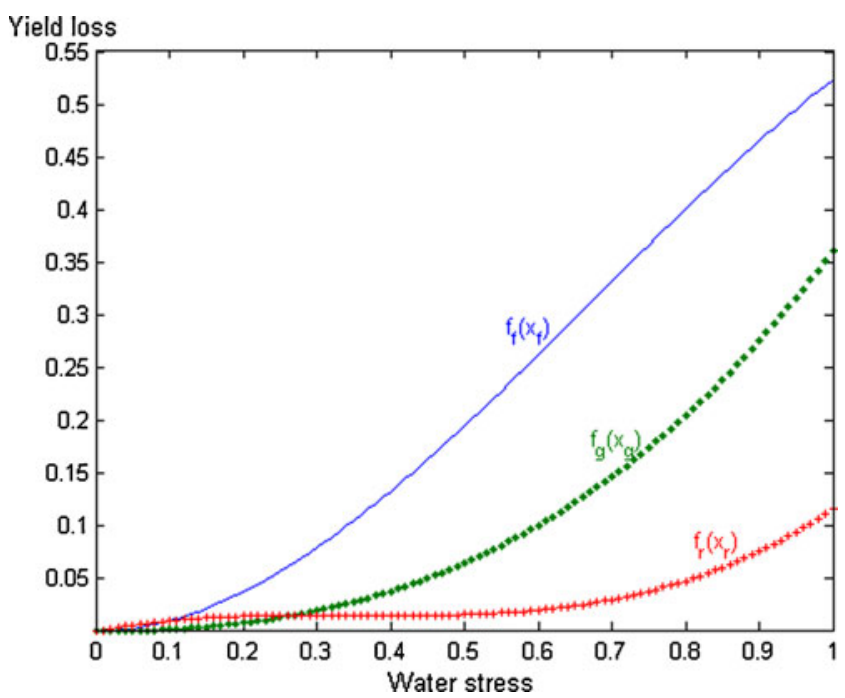

Fig. 1 Yield loss ratio as a function of water stress defined as the ratio of water supplied at each phenological stage referring to crop evapotranspiration; $\mathrm{f}, \mathrm{g}$ and $\mathrm{r}$ represent flowering, fruit growth and ripening stages, respectively

$$
\begin{aligned}
E_{\mathrm{r}} & =\left[\begin{array}{llll}
-0.1108 & 0.1003 & -0.0777 & 0.0455
\end{array}\right]^{T} \rightarrow E_{\mathrm{RMS}}=0.0304 \\
R^{2} & =1-\frac{F^{2}}{F_{0}^{2}}=0.9959
\end{aligned}
$$

where $f$ represents the yield loss functions; $x_{\mathrm{f}}, x_{\mathrm{g}}$ and $x_{\mathrm{m}}$ are the water restrictions in terms of $\mathrm{ET}_{\mathrm{C}} ; E_{\mathrm{r}}$ the relative error vector and $E_{\mathrm{RMS}}$ the root mean squared error and $R^{2}$ the Nash-Sutcliffe coefficient.

In terms of this analysis, flowering and fruit growth would be the most sensitive phenological stages. Accordingly, a water restriction approaching $50 \%$ would promote a yield loss of less than $10 \%$ when applied during fruit growth and $20 \%$ when applied during flowering. On other hand, it would be necessary to apply a water restriction of nearly $100 \%$ of $\mathrm{ET}_{\mathrm{C}}$ during the ripening period in order to limit the production loss to roughly $10 \%$.

Established crop water production functions are based on linear relationships proposed by Doorenbos and Kassam (1979), assuming that irrigation is applied with the goal of fully meeting plant water requirements, without considering the crop yield response to DI strategies. Another relevant question is related to the effect of DI in yield models when the deficit is applied at different phenological stages. In this sense, data normalization becomes necessary for all the terms of yield response ratio and relative irrigation, as was studied in the present work, separating the seasonal crop yield variation. Along this line, Hexem and Heady (1978) proposed several non-linear crop production functions (i.e., quadratic, Cobb-Douglas and Mitscherlich-Spillman), in which irrigation water applied was related to the crop yield ratio, with better results than linear relationships. Similar models were applied by Martin et al. (1984), achieving highly significant functions.

\subsection{Adjustment by adding cross terms}

In view of the above results, the addition of cross terms was considered for estimating the partial and total fruit yield loss, when a water restriction is applied in a single (or various) phenological stage(s), by assuming that the water stress applied at two different stages would have a greater impact on yield loss than by inducing the water stress separately. However, if water stress is induced in one stage, fruit yield is reduced; therefore, inducing water stress at a later stage should not affect the yield that has already been previously lost. Under these considerations, the new croploss functions were determined by assuming the different water stress combinations for all phenological periods and the cross terms were established as indicated by Eq. 6 .

According to the analysis with cross terms, these results are consistent with the influence at the different stages, where ripening is the less influential (Fig. 2). Finally, by 


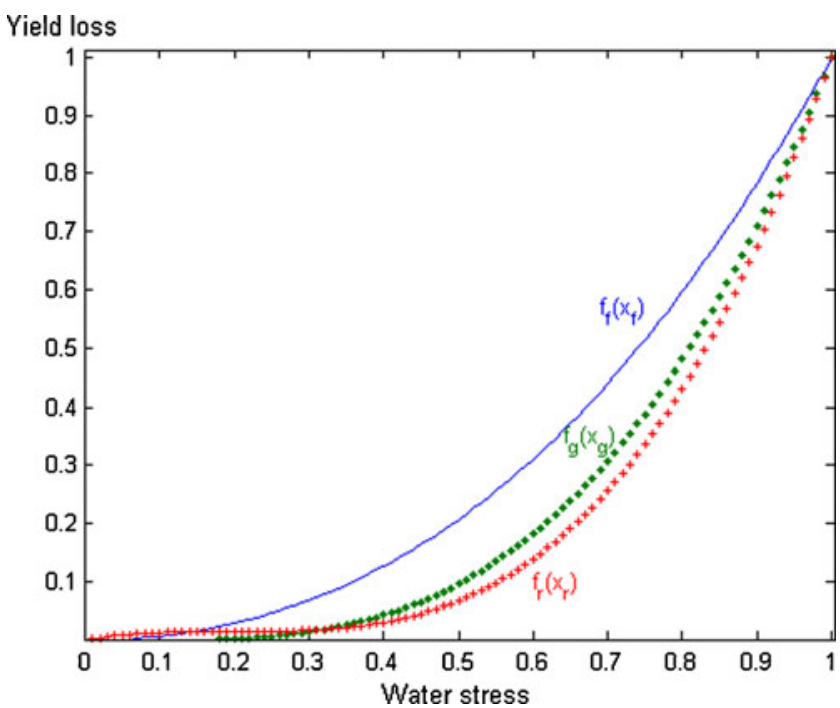

Fig. 2 Stand-alone components of yield loss ratio as a function of water stress, defined as a ratio of the water supplied at each phenological stage referring to crop evapotranspiration; $f, g$ and $r$ represent flowering, fruit growth and ripening stages, respectively

considering the sum of global terms, the final expression and the relative error vector are defined by:

$$
\begin{aligned}
& f(\vec{x})=f_{\mathrm{f}}\left(x_{\mathrm{f}}\right)+f_{\mathrm{g}}\left(x_{\mathrm{g}}\right)+f_{\mathrm{r}}\left(x_{\mathrm{r}}\right)-f_{\mathrm{f}}\left(x_{\mathrm{f}}\right) f_{\mathrm{g}}\left(x_{\mathrm{g}}\right)-f_{\mathrm{f}}\left(x_{\mathrm{f}}\right) f_{\mathrm{r}}\left(x_{\mathrm{r}}\right) \\
& -f_{\mathrm{g}}\left(x_{\mathrm{g}}\right) f_{\mathrm{r}}\left(x_{\mathrm{r}}\right)+f_{\mathrm{f}}\left(x_{\mathrm{f}}\right) f_{\mathrm{g}}\left(x_{\mathrm{g}}\right) f_{\mathrm{r}}\left(x_{\mathrm{r}}\right) \\
& f_{\mathrm{f}}\left(x_{\mathrm{f}}\right)=0.3404 x_{\mathrm{f}}^{3}+0.6596 x_{\mathrm{f}}^{2} \\
& f_{\mathrm{g}}\left(x_{\mathrm{g}}\right)=1.2658 x_{\mathrm{g}}^{3}-0.2848 x_{\mathrm{g}}^{2}+0.019 x_{\mathrm{g}} \\
& f_{\mathrm{r}}\left(x_{\mathrm{r}}\right)=1.9144 x_{\mathrm{r}}^{3}-1.1411 x_{\mathrm{r}}^{2}+0.2267 x_{\mathrm{r}} \\
& \mathrm{E}_{r}=\left[\begin{array}{llll}
-0.0707 & 0.0583 & -0.0381 & 0.0253
\end{array}\right]^{T} \rightarrow E_{\mathrm{RMS}}=0.0105 \\
& R^{2}=1-\frac{F^{2}}{F_{0}^{2}}=0.9995
\end{aligned}
$$

where $f$ is the crop-loss function; $x_{\mathrm{f}}, x_{\mathrm{g}}$ and $x_{\mathrm{m}}$ are the water restrictions in terms of $\mathrm{ET}_{\mathrm{C}} ; E_{\mathrm{r}}$ is the relative error vector and $E_{\mathrm{RMS}}$ the root mean squared error and $R^{2}$ is the NashSutcliffe coefficient. We can also evaluate the improvement induced by the introduction of the cross terms to our model:

$r^{2}=\frac{R_{2}^{2}-R_{1}^{2}}{1-R_{1}^{2}}=0.87$

Figure 3 shows the effect of applying water stress during two or three phenological periods. Taking these results into account, we found that, when water stress was applied during flowering and another stage, the yield loss was especially noticeable, this being the determining period for final yield. In this sense, when water stress was not applied during the flowering period, yield loss was significantly lower than in other situations.

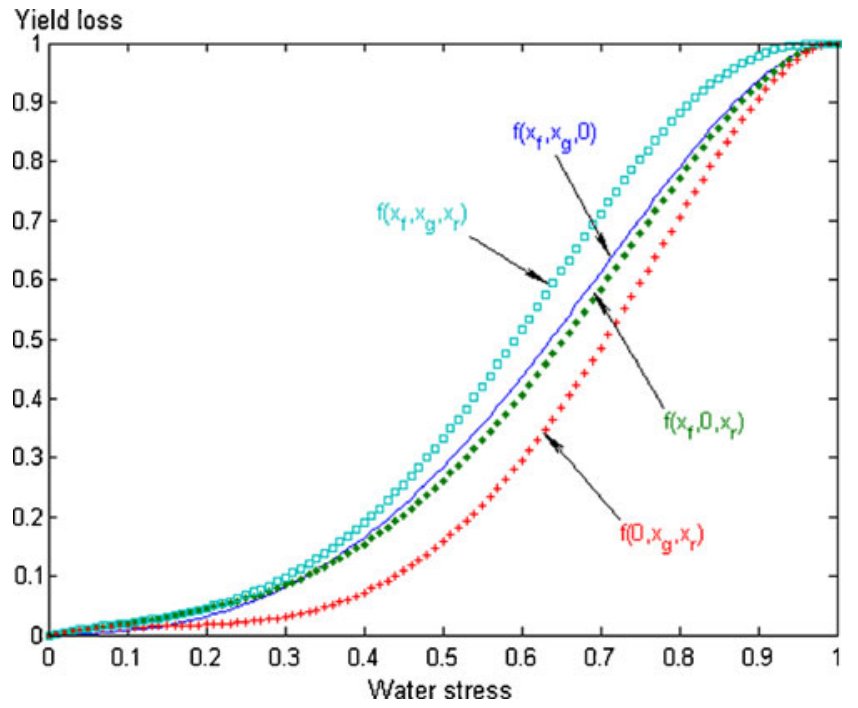

Fig. 3 Effect of applying water stress at multiple stages on the yield loss ratio. Water stress is defined as the ratio of water supplied at each phenological stage referring to crop evapotranspiration. $f$, $g$ and $r$ represent flowering, fruit growth and ripening stages, respectively

The grade 3 was chosen for the yield functions after trials with grades 2 and 4 (Table 2). From the results (1), the grade 2 functions registered a low efficiency index $(0.80)$, and the cross terms had only a marginal effect $\left(r^{2}=0.0847\right)$; (2) the grade 3 functions halved the $E_{\text {RMS }}$ and showed an efficiency index of close to one. The addition of the cross terms strongly improved the efficiency $\left(r^{2}=0.87\right)$; and (3) the grade 4 functions halved the $E_{\mathrm{RMS}}$ and, after adding the cross terms, reached the maximum efficiency (1). Considering the yield function of grade 3, we compared the measured vs. the estimated yield loss ratio for each RDI and season (Table 3), which showed a good fit with differences ranging between -0.05 and 0.04 . These results evidence significant accuracy for estimating a yield loss when water stress is applied during two or more phenological periods. Thus, the grade 3 functions offered a quite accurate approximation.

When water deficit was applied during a given stage, the crop response depended on the magnitude and time

Table 2 Error and efficiency index for models at different grade functions

\begin{tabular}{lllll}
\hline Function grade & & 2 & 3 & 4 \\
\hline Without cross terms & $E_{\mathrm{RMS}}$ & 0.0597 & 0.0304 & 0.0171 \\
& $R^{2}$ & 0.7922 & 0.9959 & 0.9988 \\
\multirow{2}{*}{ With cross terms } & $E_{\mathrm{RMS}}$ & 0.0105 & 0.0105 & 0.0029 \\
& $R^{2}$ & 0.8098 & 0.9995 & 1 \\
$r^{2}$ & & 0.0847 & 0.8700 & 1
\end{tabular}

$E_{R M S}$ root mean squared error, $R^{2}$ Nash-Sutcliffe efficiency coefficient, $r^{2}$ model improvement index 
Table 3 Measured vs. predicted yield reduction ratios as a function of control treatment for each RDI and monitored season

\begin{tabular}{|c|c|c|c|c|c|c|c|c|c|}
\hline \multirow[t]{2}{*}{ Treatments } & \multicolumn{3}{|l|}{ 2005-2006 } & \multicolumn{3}{|l|}{ 2006-2007 } & \multicolumn{3}{|l|}{ 2007-2008 } \\
\hline & Measured & Predicted & Difference & Measured & Predicted & Difference & Measured & Predicted & Difference \\
\hline RDI-1 & 0.19 & 0.21 & 0.02 & 0.15 & 0.19 & 0.04 & 0.18 & 0.20 & 0.02 \\
\hline RDI-2 & 0.15 & 0.19 & 0.04 & 0.16 & 0.17 & 0.01 & 0.23 & 0.18 & -0.05 \\
\hline RDI-3 & 0.21 & 0.23 & 0.02 & 0.19 & 0.21 & 0.02 & 0.26 & 0.22 & -0.04 \\
\hline RDI-4 & 0.08 & 0.11 & 0.03 & 0.07 & 0.11 & 0.04 & 0.11 & 0.12 & 0.01 \\
\hline
\end{tabular}

$R D I$ regulated deficit irrigation

of water stress. These effects differed with crop species and varieties, as well as crop sensitivity to water stress at a given stage. We have defined different yield response factors $\left(K_{Y}\right)$ according to the methodology proposed by many authors (Stewart and Hagan 1973; Azaiez and Hariga 2001; Houndari and Azaiez 2001). However, Stewart and Hagan (1973) showed different relations between yield and crop evapotranspiration, developing a multiplicative equation for crop yield as a function of the irrigation water applied.

On other hand, Hexem and Heady (1978) defined a general equation for defining the water production function as a third-order polynomial. Kipkorir et al. (2002) found a highly significant fit of second- and third-order polynomials, for onions and maize, respectively.

In general, the effects of water stress at different periods interact in a complex manner, although in most cases simplifications are introduced by assuming that the stress effects in each period are independent. Consequently, the combined effects of water stress over several periods are evaluated assuming that these effects are additive or multiplicative, despite that these models require calibration locally, as stated by Rao et al. (1988), who reported that dated production functions are location specific.

Within a framework of water scarcity, DI strategies could be key in possible future scenarios of water shortage, enabling the maintenance of agro-ecosystems under limiting conditions. In this context, Severini and Cortignani (2008) proposed a positive mathematical programming model for studying the viability of deficit irrigation strategies, arguing that these techniques effectively describe the negative impact of decreasing water availability on farm economic results. In addition, Azaiez (2008) developed an integral dynamic programming model for analysing the effects of DI in order to increase the irrigated area at the expense of reducing the crop yield per unit area, considering that the effects of DI are closely related to the amount of water applied for each phenological period.

\section{Conclusions}

These new functions improve our knowledge concerning the relationship between water stress and citrus yield and therefore its implications for sustainable management of available water resources. According to the results of the present study, the new proposed model for explaining the combined effect of deficit irrigation in several periods would be an additive-multiplicative model, considering that the effect of water stress in previous stages determines the crop yield response when DI is applied at the various stages. Our models indicate that the crop water production function under DI programmes would have a quasi-linear relation for water deficits below to $40 \% \mathrm{ET}_{\mathrm{C}}$.

We conclude that multiplicative models considering the addition of cross terms are more applicable over a wide range of stress conditions, especially when irrigation water stress is applied during two or more phenological stages; meanwhile, the simple models without considering crossterm addition would be feasible when DI stress is applied only during one of these stages. Also, assuming the relationship between water stress and yield loss, we deduce that flowering and fruit growth periods are more sensitive to DI than is the ripening period. Thus, the models developed could be considered a preliminary step for achieving precise sustainable water management under DI programmes in citrus cultivation, especially in situations of water scarcity, which are occurring with alarming frequency in semi-arid areas.

Acknowledgements The authors acknowledge the support of research project RTA2008-00058-CO3-03 co-financed with FEDER funds (European Union). I. Garcia-Tejero received a research fellowship from INIA (PRE-2007). The authors also thank J. GarcíaBaquero and M.A. Fernández-Ayala for the field data collection and laboratory analyses. 


\section{References}

Azaiez MN (2008) Modeling optimal allocation of deficit irrigation: application to crop production in Saudi Arabia. J Math Model Algor 7:277-289. doi:10.1016/S0377-2217(00)00212-5

Azaiez MN, Hariga M (2001) A single period model for conjunctive use of ground and surface water under severe overdrafts and water deficit. Eur J Oper Res 133:653-666

Byung-Gook L, Yunbeom P (1998) Approximate conversion of rational Bézier curves. J KSIAM 2:88-93

Castel JR (1991) El riego de los cítricos. Hortifruticultura 5:41-52

Chalmers DJ, Burge G, Jerie PH, Mitchell PD (1986) The mechanism of regulation of Bartlett pear fruit and vegetative growth by irrigation withholding and regulated deficit irrigation. J Am Soc Hort Sci 111:904-907

Doorenbos J, Kassam AH (1979) Yield response to water. FAO Irrigation and Drainage paper no. 33.

Doorenbos J, Pruitt WO (1977) Las necesidades de agua de los cultivos. Estudio FAO. Riegos y Drenaje 24. FAO, Rome

FAO (1998) World reference base for soil resources. Food and Agriculture Organization of the United Nations, Rome

Fletcher R, Powell MJD (1963) A rapidly convergent descent method for minimization. Comp J 6:163-168

García-Tejero I, Jiménez JA, Reyes MC, Carmona A, Pérez R, Muriel JL (2008) Aplicación de caudales limitados de agua en plantaciones de cítricos del valle del Guadalquivir. Frutic Prof 173:5-17

García-Tejero I, Durán ZVH, Muriel JL, Rodríguez PCR (2011a) Water and sustainable agriculture. In: Springer Briefs in Agriculture. doi: 10.1007/978-94-007-2091-6

García-Tejero I, Durán ZVH, Muriel JL, Martínez GG, Jiménez BJA (2011b) Benefits of low-frequency irrigation in citrus orchards. Agron Sustain Dev 31:779-791. doi:10.1007/ s13593-011-0025-1

Gill PE, Murray W, Wright MH (1981) Practical optimization. Academic, London

Goldhamer DA, Salinas M (2000) Evaluation of regulated deficit irrigation on mature orange trees grown under high evaporative demand. In: Albrigo LG (ed) Proceedings of the 9th Congress of the International Society of Citriculture. Global Citrus Germplasm Network, Orlando, pp 227-231
González-Altozano P, Castel JR (2000) Regulated deficit irrigation on 'Clementina de Nules' citrus trees. II. Vegetative growth. J Hort Sci Biotech 75:388-392

González-Altozano P, Castel JR (2003) Riego deficitario controlado en clementina de nules I. Efectos sobre la producción y la calidad de la fruta. Span J Agric Res 1:81-92

Hexem RW, Heady EO (1978) Water production functions for irrigated agriculture. Center for Agricultural and Rural Development, Iowa State University Press, Ames

Houndari M, Azaiez MN (2001) Optimal cropping patterns under water deficit. Eur J Oper Res 130:133-146. doi:10.1016/S03772217(00)00028-X

Jensen ME (1968) Water consumption by agricultural plants. In: Kozlowski TT (ed) Water deficit and plant growth, vol 2. Academic, New York, pp 1-22

Kipkorir EC, Raes D, Massawe B (2002) Seasonal water production functions and yield response factors for maize and onion in Perkerra, Kenya. Agric Water Manag 56:229-240. doi:10.1016/ S0378-3774(02)00034-3

Martin DL, Watts DG, Gilley JR (1984) Model and production function for irrigation management. J Irrig Drain Eng 110:149 164. doi:10.1061/(ASCE)0733-9437(1984)110:2(149)

Moriasi DN, Arnold JG, Van Liew MW, Bingner RL, Harmel RD, Veith TL (2007) Model evaluation guidelines for systematic quantification of accuracy in watershed simulations. Trans ASABE St Joseph Mich 50:885-900

Nash JE, Sutcliffe JV (1970) River flow forecasting through conceptual models part I-a discussion of principles. J Hydrol 10:282-290. doi:10.1016/0022-1694(70)90255-6

Rao NH, Sarma PBS, Chander S (1988) A simple dated waterproduction function for use in irrigated agriculture. Agric Water Manag 13:25-32. doi:10.1016/0378-3774(88)90130-8

Severini S, Cortignani R (2008) Introducing deficit irrigation crop techniques derived by crop growth models into a positive mathematical programming model. 12th Congress of the European Association of Agricultural Economist. EAAE, The Hague

Stewart JI, Hagan EM (1973) Functions to predict effects of crop water deficits. J Irrig Drain Div ASCE 99:421-439

Stewart JI, Cuenca RH, Pruitt WO, Hagan RM, Tosso J (1977) Determination and utilization of water production functions for principal California crops. W-67 CA. Contributing Project Report. University of California, Davis 